Artículo de reflexión

Cómo citar: Baldoví, J. (2019). De la literatura como una de las disciplinas complejas y de la competencia de los escritores de ficción para instituirse en anfibios culturales. Praxis Pedagógica, 19(25), 77-109. http://dx.doi.org/10.26620/ uniminuto.praxis.19.25.2019.77-109

ISSN: 0124-1494

eISSN: $2590-8200$

Editorial: Corporación Universitaria Minuto de Dios - UNIMINUTO

Recibido: 7 de enero de 2019

Aceptado: 1 de marzo de 2019

Publicado: 5 de agosto de 2019

Conflicto de intereses: los autores han declarado que no existen intereses en competencia.

\section{De la literatura como una de las disciplinas complejas y de la competencia de los escritores de ficción para instituirse en anfibios culturales ${ }^{1}$}

\author{
Literature as one of the complex \\ disciplines and the competence \\ of fiction writers to institute \\ themselves as cultural amphibians
}

José María Baldoví Giraldo https://orcid.org/0000-0001-6360-8126 Pontificia Universidad Javeriana baldogi@hotmail.com Colombia

\author{
A literatura como uma das disciplinas \\ complexas e a competência \\ dos escritores de ficção para se \\ instituírem em anfíbios culturais
}

\section{Resumen}

La literatura es una forma holística de conocer el mundo, tal como lo fueron los mitos y lo ha sido la novela de anticipación o de ciencia-ficción. La narrativa no solo indaga e interpreta el interior del hombre, sino que establece puentes con el mundo exterior y las ciencias para configurar una visión total del mundo. El arte de contar va más allá de la ensoñación; es también enlazar, reunir, conjugar y

1 José María Baldoví Giraldo es autor del libro Recortes. Textos de periodismo literario (Ecoe Ediciones, 1988), de un volumen de relatos breves: El pie del capitán Blake y otros cuentos demoledores (Esquina Tomada Ediciones, 2018), y de dos novelas: Alcánzame las gafas (Uniediciones, 2017) y El retrato (Uniediciones, 2020). 
ordenar aquello que está separado para ofrecer una visión compleja del adentro y del afuera. Este religar integra obra y sentido; acción y destino; ciencia y significado.

Palabras clave: literatura, complejidad, cultura, Morin, de Sousa Santos, Estanislao Zuleta, la narrativa como forma de conocimiento, anfibios culturales.

\begin{abstract}
Literature is a holistic way of knowing the world, just as myths were and has been the novel of anticipation or science fiction. The narrative not only investigates and interprets the inside of man, but also builds bridges with the outside world and the sciences to form a total vision of the world. The art of counting goes beyond dreaming; it is also about linking, gathering, conjugating and ordering that which is separate to offer a complex vision of the inside and the outside. This integrates work and meaning; action and destiny; science and meaning.
\end{abstract}

Keywords: Literature, complexity, culture, Morin, de Sousa Santos, Estanislao Zuleta, narrative as a form of knowledge, cultural amphibians.

\title{
Resumo
}

A literatura é uma forma holística de conhecer o mundo, tal como os mitos foram e têm sido o romance da antecipação ou da ficção científica. A narrativa não só investiga e interpreta o interior do homem, mas também constrói pontes com o mundo exterior e as ciências para formar uma visão total do mundo. A arte de contar vai além do sonho; é também ligar, reunir, conjugar e ordenar aquilo que é separado para oferecer uma visão complexa do interior e do exterior. Este religar integra trabalho e significado; ação e destino; ciência e significado.

Palavras-chave: Literatura, complexidade, cultura, Morin, de Sousa Santos, Estanislao Zuleta, narrativa como forma de conhecimento, anfíbios culturais. 


\section{Introducción}

Dice Kundera (1994) en El arte de la novela: "Sólo creo saber que la novela ya no puede vivir en paz con el espíritu de nuestro tiempo: si todavía quiere seguir descubriendo lo que no está descubierto, si aún quiere "progresar" en tanto que novela, no puede hacerlo sino en contra del progreso del mundo" (p.'30). Esta especie de imperativo categórico o programa ideológicoestético parece invitarnos a una seria reflexión acerca del quehacer más profundo y comprometido de la escritura artística en prosa. Esa acción literaria en contra del progreso del mundo, en función del pensamiento complejo, podría entenderse, por lo menos, desde dos perspectivas. La primera: como ejercicio crítico acerca de lo que los tiempos actuales predican, y lo que predican es que la industria, la tecnología y la ciencia han tomado el comando de la cultura y dictan un "estilo de vida", pues sus inventos y productos ejercen una influencia irrevocable. Influyen en nuestros actos, en nuestros pensamientos, hasta en nuestros sentimientos. Nada escapa al ojo, al cerebro y a la mano cibernéticos. Esa inabarcable red digital ve, piensa, actúa y "siente" por nosotros.

En consecuencia, las realizaciones de las ciencias están a punto de destronar el discernimiento. La ciencia afirma que la farmacología es más eficaz que nunca, sin embargo, el cuerpo humano ha desarrollado una capacidad de resistencia a los efectos de ciertas drogas, razón por la cual están surgiendo nuevas y desastrosas enfermedades.

Se alega que la tecnología digital ya está al alcance de cualquiera con el fin de acceder al conocimiento. Sin embargo, esa misma tecnología, por sí sola, no puede discriminar entre una información cierta y otra apócrifa. Igualmente, la automatización está reemplazando nuestros talentos, en lugar de expandirlos. Y el mundo de la industria, en virtud de su poder incontestable, contamina las fuentes naturales de la vida.

Dicho de otra manera, la ciencia, la tecnología y la industria avanzan con anteojeras, sin darse cuenta de los estragos que puedan estar causando a su alrededor. Ese progreso, sin duda intercomunicado, corporativo y multidisciplinar, que luce tan brillante y robustecido, no siempre garantiza una finalidad humana, pues las pretendidas mejoras de las condiciones 
materiales de la existencia no se reflejan en disminución del hambre, la injusticia, la violencia, la enfermedad y la ignorancia.

La segunda perspectiva compleja y complejizante respecto al progreso del mundo consiste en que las humanidades, y las letras son parte de ellas, no cuentan con la "jerarquía" suficiente como para que las ciencias las incorporen en su trayecto, inmune a los discursos de la novela, la filosofía, las ciencias sociales, incluso el proveniente de los saberes ancestrales.

De manera tal que resulta apremiante que esa otra mirada, la propia de los saberes, haceres y pensares de la órbita poética, en cuanto visión de una existencia imbuida de belleza, ética, conocimiento ancestral y crítica filosófica, intervenga en la práctica científica para que esta acoja una dimensión más abarcadora y estética de la vida. Es decir, el saber científico precisa emparentarse con el saber literario y humanístico para ampliar su marco epistemológico. Así que la producción tecnológico-instrumental es susceptible de un ars poética, lo que significa que es posible superar el dualismo entre la descripción científica y la significación letrada para que el experimento, el procedimiento metodológico y el artefacto sean considerados a la luz de lo que Pablo Antonio Cuadra denominó el retorno a la fuente del canto: encontrar la poesía de las cosas corrientes (Cuadra, s.f.).

Esta poesía de las cosas corrientes no es más que la finalidad humana de toda obra. Además, no hay que olvidar que el poeta, es decir, el creador literario, es un hacedor de formas, de sentidos, de significaciones, y un hacedor de puentes, conexiones, reuniones y recomposiciones. Justamente esto es pensamiento complejo. Son pues el novelista y el humanista genuinos complejólogos. Si esto es así, entonces podemos proponer para los creadores literarios la categoría de anfibios culturales, es decir, traductores, intérpretes de mundos: el de la materia y el del hombre.

De manera que el objetivo de este trabajo consiste en considerar a la literatura como disciplina clave del pensamiento complejo, e igualmente evaluar la contribución que los autores literarios pueden realizar a la investigación científica a partir del filtro de la imaginación, la estética y la mirada poética. Además, la 
capacidad de apertura y asimilación del mundo exterior, por un lado, y la de indagar por el mundo interior del hombre, por el otro, permiten pensar que los escritores cuentan con la competencia para erigirse en puentes de las dos culturas, concepto este que propusiera C. P. Snow en Las dos culturas (2000).

Aquí se sostiene que científicos y novelistas sueñan, proyectan y desentrañan el mundo según sus lenguajes, reglas, métodos, finalidades, objetos de estudio, en fin; lo que significa que coinciden en cuanto a la contemplación de un cosmos que debe ser comprendido y sobre el cual se crean determinadas imágenes, al igual que unos y otros cumplen con el precepto de dudar, es decir, de indagar.

\section{De la introspección al cosmos}

Así como la teoría del caos, o efecto mariposa, es uno de los elementos constitutivos de la complejidad, no lo es menos la belleza, concepto que a pesar de la subjetividad que entraña, remite, en todo caso, a la armonía, por cuanto refleja el equilibrio de las proporciones entre las distintas partes de un todo, de manera tal que no hay sistema u organización que no tienda a alguna forma de belleza. Aun en la fragmentación, la asimetría y la irregularidad, el universo adopta un cierto orden, procura una cierta distribución, busca una determinada disposición.

Pero no solo la estética de las relaciones interviene en la configuración de la complejidad. Las artes y las letras son la prueba más palmaria de que lo complejo ha sido captado y desarrollado por la pintura, la música y la literatura. El monólogo interior permitió el examen introspectivo, reveló la desconexión del hombre consigo mismo y más tarde asimiló el psicoanálisis. El impresionismo puso en evidencia el malestar social y la degradación del hombre. Y la música contemporánea ha intentado darle sonido al desconcierto en el que vive el mundo.

En síntesis, si a lo largo de la historia ha habido un vehículo de expresión para poder entender el mundo, ese ha sido la metáfora, que además de significar ir más allá de algo, ha permitido que las cosas o conceptos más disímiles y opuestos encuentren un punto en común. No riñe pues la metáfora con la complejidad, siendo como es esta, en cierto sentido, una correlación de semejanzas. 
Así, de Sousa Santos (2009b) y Morin (1999) están de acuerdo, de manera explícita, en que la naturaleza y el mundo son manifestaciones plásticas y bellas por sí mismos, dignos de contemplación, de cuidado y de una interpretación más inteligente y comprensiva.

Por tanto, el mundo es una escultura, un texto, un relato sobre el que ya no se arroja una mirada crítica, sino que se percibe como otro sujeto con el que se mantiene una relación interpretativa. Cada uno, sujeto humano y sujeto natural, ejerce una traducción del otro, que ya no es un oponente, sino, más bien, una interrogación, un complemento, una posibilidad de realización total. Al respecto, retomo lo expresado por de Sousa Santos (2009b)

La creación científica en el paradigma emergente se asume como próxima a la creación literaria o artística, porque a semejanza de éstas pretende que la dimensión activa de la transformación de lo real (el escultor trabaja sobre la piedra) sea subordinada a la contemplación del resultado (la obra de arte). A su vez, el discurso científico se aproxima cada vez más al discurso de la crítica literaria. De algún modo, la crítica literaria anuncia la subversión de la relación sujeto/objeto que el paradigma emergente pretende operar (p. 54).

De esta forma, la posibilidad plástica de las ciencias, en el sentido de supresión de los límites particulares de cada una de ellas y su amplia gama de interrelaciones, como la abolición de fronteras entre el observador y lo observado, ha proporcionado un sentido nuevo a la investigación y al relato del saber, hasta el punto que podríamos decir que el arte se viene manifestando a través de la complejidad de la realidad. Una operación equivalente ocurrió cuando Baudelaire elevó a poesía la miseria que encontró a su paso por las calles de París. Masas largas, amorfas y purulentas se convierten en pretextos literarios. Los bajos fondos de la cité empezaron a poblar el lenguaje urbano y brutal de la estética modernista. Ahora, cuando el hombre está fuera de su pedestal, descubre que en la organización del mundo existe un texto por leer, un lienzo por colorear o una partitura por tocar.

No exageramos si sostenemos que la emoción estética puede ser un punto de acuerdo entre las ciencias de la complejidad y el pensamiento complejo, pues la prosa, por decirlo así, de las primeras, tendrían algo en común, una misteriosa unidad 
con la poética del pensar: ese algo misterioso se acercaría a las Iluminaciones de Rimbaud, esas vibrantes imágenes de poesía en prosa del entonces naciente simbolismo francés. Este otro simbolismo consistiría, si es que no consiste ya, en una desocultación que se realizaría a partir de la sinestesia, ese recurso que asocia los sentidos con las sensaciones. Es decir, que al pensamiento y a las ciencias de complejidad les cabría la misión de traducir a metáforas el diálogo de los planetas, las partículas y las moléculas. Así, esta visión comprobaría la creatividad que asiste al hacer $y$ al pensar.

Algo por el estilo manifiesta Morin (1999), que pone la literatura al servicio de la comprensión de la complejidad, porque la literatura es la complejidad misma, y sobre todo porque es metáfora de la realidad por excelencia.

Así es como dice Morin (1999) en Epistemología de la complejidad:

soy sensible a los poderes, a los encantos de la connotación. [...] Ante todo, hago metáforas sabiendo que son metáforas. [...] Es sabido que la historia de las ciencias está hecha de migración de conceptos, es decir, literalmente, de metáforas (p. 160).

De modo que el lenguaje figurado no ha sido, en contra de lo que se pudiera creer, un desfigurador ni necesariamente un embellecedor de la realidad, sino más bien lo contrario, pues no solo forma parte de la realidad lingüística, sino que va más allá porque conceptualmente integra el sistema de pensamiento, que discierne también mediante analogías, comparaciones, contrastes y traslapes.

En El paradigma de complejidad, Morin (1999) encabeza su reflexión diciendo que

la complejidad en ese dominio (el de la vida cotidiana) ha sido percibida y descrita por la novela del siglo XIX y comienzos del XX. [...] El tema del monólogo interior, tan importante en la obra de Faulkner, era parte de esa complejidad. [...] ésta (la novela) nos reveló también que cada uno se conoce muy poco a sí mismo (p. 87).

Este conocerse poco a sí mismo del hombre no es más que el principio del conocimiento, el fin paulatino de las apariencias, la derrota del engaño, el reconocimiento de una ignorancia 
que en lo sucesivo deja de ser un obstáculo para la formación de la conciencia. Si a la literatura vamos, no es difícil entender que la vida cotidiana que en ella tiene lugar revela los distintos rostros que cada uno de los personajes (cada uno de nosotros) desempeña en los distintos sistemas sociales.

Agrega Morin (1999) que "vemos así que cada ser tiene una multiplicidad de identidades, una multiplicidad de personalidades en sí mismo, un mundo de fantasmas y de sueños que acompañan su vida" (p.87). De modo que obras como En busca del tiempo perdido, de Marcel Proust, Los hermanos Karamazov, de Dostoyevski, o Mientras agonizo, de Faulkner, nos indican que no solo el sistema social es complejo, sino que cada ser humano lleva en sí una serie de capas o pliegues que lo configuran, pues los hechos externos se narran según las vivencias de los personajes, el tiempo cronológico le cede el paso al tiempo psicológico e incluso el narrador, para darle cabida a la conciencia, se convierte en un investigador cuyo objeto de estudio es su propio yo.

De esta forma se puede colegir que el arte es también una fuente de conocimiento, pues cuenta con recursos, métodos, estrategias y caminos para explorar la intimidad de la vida humana. Es más. Tal vez hay cosas que solo la literatura puede expresar. Tal como sucede en un verso de Hay una luz en primavera de Emily Dickinson, recogido por Aldous Huxley (1966) en su obra Literatura y Ciencia: "Hay un color extraño en las colinas solitarias que no puede comprender la ciencia y el hombre siente" (p. 29).

La experiencia íntima de un hecho inefable encuentra manifestación en la purificación de un lenguaje constituido por la intuición y el arcano. Es como una invocación del memento mori. También puede aludir al efecto psicológico que el ocaso produce en la autora. O la admonición del fin del mundo. Aquí, la escritora intenta proponer un lenguaje que recoja el múltiple significado de una sensación que va más allá de un mensaje genético, de la anticipación de un eclipse, de la inevitabilidad del colapso del organismo. Dicho de otro modo, el lenguaje literario puede interpretarse de muchas maneras, el científico, solo de una.

Sin embargo, la complejidad no elimina el sentido estético del arte ni aísla el dato concreto de la realidad: intenta ensamblar 
sensación profunda con el acontecimiento exterior. Tal vez a ese propósito de articulación entre el espíritu y la materia responda aquella frase panteísta de Morin (1981): "Me he sentido conectado con el patrimonio planetario, animado por la religión de lo que une, el rechazo de lo que rechaza, una solidaridad infinita; lo que el Tao Ilama el espíritu del valle 'recibe todas las aguas que se vierten en él'" (p. 39).

La virtud de la complejidad consistiría en acoger la ambigüedad de la realidad, en tratar de conciliar la claridad de la ciencia y la sutilidad de la poesía. Tarea nada fácil, pues se trata de poner de acuerdo la expresión precisa o técnica de las ciencias y la palabra más personal, más inusitada de la locución literaria. Creadores y científicos aspiran a comunicar experiencias incomunicables mediante el empleo del lenguaje corriente, aunque coincidentes en la aceptación de la pluralidad de un mundo henchido de misterio, emergencias, azar e incertidumbre.

No por acaso literatura y ciencia pueden prestarse mutuos y benéficos servicios para admirar la realidad indivisa, pues en las revelaciones del artista se perciben y hasta anticipan aquellas realidades que luego captan los instrumentos científicos. Al respecto, cito en extenso:

La biología, es evidente, tiene una más estrecha conexión con la experiencia humana que las ciencias de la física y la química, que poseen una mayor exactitud. De ahí su especial importancia para todos los escritores. Las ciencias de la vida pueden confirmar las intuiciones del artista, pueden profundizar sus presentimientos y extender el alcance de su visión. Los escritores, los directores espirituales y los hombres de negocios, "toda esa gente", escribe el profesor A.H. Maslow, "pueden tener maravillosas intuiciones, plantear los interrogantes que es necesario preguntar, proponer hipótesis desafiantes e incluso pueden resultar casi siempre verdaderas. Pero por seguros que ellos se sientan, no pueden hacer que a la humanidad le suceda lo mismo... La ciencia es el único medio que poseemos para que una garganta desganada trague la verdad. Sólo la ciencia puede superar las diferencias caracterológicas que influyen en la visión y la creencia. Sólo la ciencia puede progresar".

Las ciencias de la vida necesitan las intuiciones del artista e, inversamente, el artista necesita todas las ciencias que puedan ofrecerle nuevos materiales sobre los cuales ejercer 
sus capacidades creadoras. Y la humanidad en general -la raza de multiplicidad anfíbica que vive inquietamente en el mismo y único momento en cuatro o cinco universos diferentes y dispares- necesita las síntesis que sólo el hombre de letras con "a heart that waches and receives" [un corazón que observa y recibe] la perspectiva de vuelo de pájaro de la ciencia pueden procurar (Huxley, 1964, pp. 95-96).

Una muestra de que las intuiciones y premoniciones de literatos y artistas pueden cristalizarse, posteriormente, en hechos materiales y rotundos por cuenta de las investigaciones y los artilugios de las ciencias es la visión que el poeta y grabador William Blake (1983), místico a quien se le aparecían Cristo y sus doce apóstoles, además de fenomenal detractor de Newton, consignó en su Matrimonio del Cielo y el Infierno:

Todas las Biblias o códigos sagrados fueron la causa de los siguientes Errores:

1. Que Hombre tiene dos principios reales de existencia, a saber: un Cuerpo y un Alma.

2. Que Energía, Ilamada Mal, sólo nace del Cuerpo; y que Razón, Ilamada Bien, sólo nace del Alma. 3. Que Dios atormentará a Hombre en Eternidad por haber seguido sus Energías. Pero los Contrarios siguientes son Verdaderos:

1. Hombre no tiene Cuerpo distinto de su Alma, pues lo que Ilamamos Cuerpo es un trozo de Alma percibido por los cinco Sentidos, las principales puertas de Alma en este período de la vida.

2. Energía es la única vida, y nace del Cuerpo; y Razón es el límite o circunferencia periférica de Energía.

3. Energía es Eterno Goce. (p. 33).

En un tiempo, el de Blake, en el que ninguna ciencia del orden material contaba con los medios experimentales o los sustentos teóricos para afirmar con plenitud que el "Hombre no tiene Cuerpo distinto del Alma" y que "Energía es la única vida", el poema del inglés no solo resulta toda una audacia de la imaginación y un sugestivo programa estético. Es, por encima de todo, una formidable anticipación, un portentoso gesto de clarividencia, porque no pocos científicos y pensadores contemporáneos concuerdan sin rubor en que la realidad tangible es la manifestación del espíritu que otros denominan energía. 
Por lo demás, Blake, pionero no reconocido de la complejidad, veía al hombre como parte integral de la Naturaleza, de tal manera que, para él, los sentidos permiten la incorporación de la humanidad al ambiente natural, al tiempo que el entorno ampara a la humanidad. Como vitalista y romántico que era, no negaba Blake las constancias o discernimientos de los sentidos; tampoco admitía separación alguna entre lo vivo y lo inerte, la razón y la pasión, el hombre y el mundo. Por eso justamente denostaba de Newton, que, lógicamente, reducía la múltiple, colorida y contradictoria realidad a una categórica abstracción. No quería Blake (1983) que el hombre se encerrara en sí mismo y en sus ideas ajenas al mundo, él deseaba interrelacionar lo claro y lo velado, "ver el mundo en un grano de arena" (p. 26).

\section{Literatura: el otro relato de la realidad}

Pero no solo esa ha sido una de las misiones, por decirlo así, de los artistas, si es que les cabe alguna misión más allá de su compromiso con el arte mismo. Su tarea estética y reunificadora ha tendido a borrar fronteras artificiales para entender al hombre en su totalidad. En ese sentido, los creadores han denunciado y combatido las falsas oposiciones que por siglos han intentado separar y descuartizar la carne y el alma del ser humano con el objeto bien de disolver el yo en la comunidad, bien de retirar al individuo de la sociedad para buscar su afirmación en contra de la comunidad. El resultado de esa desmembración "técnica" y "quirúrgica" parece haber sido una manipulación al servicio de intereses apaciguadores o de exaltación del terror. O disciplina de hierro o existencia libérrima. En definitiva, una vida que bordea la esquizofrenia.

Por eso es que Zuleta (2003), a partir de su estudio sobre La montaña mágica de Thomas Mann, aborda, entre otras cosas, la drástica dicotomía a la cual ha sido sometido el hombre en aras de una ciencia y un pensamiento que más bien han coartado las posibilidades de un desarrollo humano equilibrado y de una conciencia exenta de culpa. Cito, pues, en extenso:

Otra aparente oposición que se presenta en la discusión es la de la naturaleza y el espíritu. Esta oposición es muy vieja y tiene muchas versiones, por ejemplo, la idea del cuerpo y el alma. El problema verdadero es ver al ser humano en la perspectiva de que es al tiempo un ser biológico y un ser social. Lo que tiene de cultural no es directamente biológico; no se pueden explicar 
las normas de la vida social o las lingüísticas como efectos de la evolución puramente biológica, es decir, como conductas instintivas. El hombre es un ser social al mismo tiempo que biológico, pero una versión como la cristiana convirtió esto en espíritu y cuerpo y de esta manera se creó una falsa oposición entre los que defienden el alma contra la sensualidad corporal, como los que defienden la naturaleza del cuerpo contra un alma que lo reprime. Estas falsas oposiciones se dan también por la falta de espíritu investigativo que indague de qué manera la vida social afecta el cuerpo y de qué manera lo biológico transforma al ser social. Podemos decir que lo que existe son varias formas de vivir el cuerpo, así que la manera de vivir el cuerpo los griegos es muy diferente a como lo vivían los señores feudales que gustaban de azotarse a sí mismos, idea que no calaría bien en la mentalidad de los griegos.

El hombre sólo puede entenderse en su integridad y el planteamiento adecuado del problema está en el análisis de las diferentes formas históricas de vivir el cuerpo. Hay sociedades que consideran terriblemente dolorosos ciertos problemas que en otras no se consideran de esta manera. Así, el parto entre los Cunas [pueblo amerindio localizado entre Colombia y Panamá] se considera doloroso; como no han leído la Biblia que "parirás tus hijos con dolor" no lo tienen en cuenta (pp. 272-273).

Las falsas oposiciones no han conducido necesariamente a una crítica, discusión o a una indagación. Se han prestado, por el contrario, para que tengamos que adoptar una u otra posición, y por consiguiente eludir la contradicción como parte sustantiva de la realidad. El procedimiento más inteligente, también en las artes, es el que se abastece del distanciamiento, la condensación, la descripción, la intuición y la imaginación.

Es el artista, entonces, quien realiza la operación de la transfiguración poética de la experiencia, sin que ello suponga renunciar a la búsqueda de conocimiento, pues como se sabe los más grandes escritores son aquellos que descubren un pliegue inadvertido del hombre y del mundo. En ese sentido, el creador es un médium, un auténtico mediador entre lo conocido y lo que todavía carece de corporeidad, también entre la tesis y la antítesis; es el hacedor de mundos un precursor de la síntesis. Para Zuleta (2003), que recurre a la obra de Thomas Mann para ilustrar esta intercesión, el asunto se plantea de la siguiente manera:

José, como tantos otros personajes de Thomas Mann, es una imagen del artista como mediador entre contradicciones. En su 
lenguaje mítico lo llama "hombre de la luna", apelando a los mitos egipcios por los cuales siente una profunda simpatía, sin oponerlos a los mitos judaicos sino combinándolos y mostrándolos como un nuevo registro para expresar una oculta verdad inconsciente. La luna es el emblema de la mediación, de lo intermediario; no es el sol, padre que fecunda, no es la tierra, madre que recibe la fecundación; es una figura intermedia que toma y da, que alumbra y recibe (p.24).

Po lo tanto, la literatura no puede ser considerada como una especie de pedagogía con el objeto de comunicar un conocimiento preexistente. Su verdadera razón de ser no es de naturaleza divulgativa, ni mucho menos. De ser así, la creación se limitaría a ser un altavoz de lo establecido, y si algo procura la literatura, y el arte en general, es justamente lo contrario, es decir, trastocar lo instituido, poner de cabeza la realidad, sondear las pulsaciones más profundas del hombre. La creación literaria es por sobre todo aventura, riesgo y exploración, con lo cual su cercanía a la ciencia es muy estrecha. Tanto es así, que Nietzsche (2011) en El origen de la tragedia, al definir los dos "instintos" (apolíneo y dionisiaco) del arte entre los griegos, pareciera anticiparse a la formulación más humanística de la complejidad contemporánea, por cuanto afirma que tras los auspicios del dios de los árboles y de la embriaguez reposa la unión del hombre consigo mismo y con todo lo demás; así me permito citar in extenso:

Bajo el encanto de la magia dionisiaca no solamente se renueva la alianza del hombre con el hombre: la naturaleza enajenada, enemiga o sometida, celebra también su reconciliación con su hijo pródigo, el hombre. El carro de Dioniso desaparece bajo las flores y las coronas, tirado por tigres y panteras. Metamorfoseemos en un cuadro el himno de la "alegría" de Beethoven $y$, dando rienda suelta a la imaginación, contemplemos los miIlones de seres prosternados de rodillas en el polvo. Entonces el esclavo es libre, caen todas las barreras rígidas y hostiles que la miseria, la arbitrariedad o la "moda insolente" han levantado entre los hombres. Ahora, por el evangelio de la armonía universal, cada uno se siente no solamente reunido, reconciliado, fundido, sino Uno, como si se hubiera desgarrado el velo de Maia y sus pedazos revoloteasen ante la misteriosa "Unidad primordial".

Cantando y bailando, el hombre se siente miembro de una comunidad superior: ya se ha olvidado de andar y de hablar, y está a punto de volar por los aires, danzando. Sus gestos delatan una encantadora beatitud, [...] El hombre no es ya un artista es una obra de arte: el poder estético de la naturaleza 
entera, por la más alta beatitud y la más noble satisfacción de la unidad primordial, se revela aquí bajo el estremecimiento de la embriaguez (pp. 20-21).

Vale subrayar que la Naturaleza, por tanto, es la fuente de la energía dionisiaca, la matriz de esa fuerza artística, de ese instinto liberador, y que al artista se le revela esta capacidad de identificación con los poderes primordiales como una "visión simbólica", como unas "imágenes del ensueño". Es decir, que el buril de la Naturaleza obra igualmente en el espíritu del hombre, razón por la cual lo que realice el artista no es más que un eco, una resonancia, un recuerdo, si se quiere, de lo que han dispuesto las potencias fundamentales del universo.

Luego está el dios plástico, de las formas, de la poesía, que es Apolo, aquel que sublima, mediante el arte y el ejercicio de la razón, la visión de la Naturaleza, al tiempo que indaga en el abismo o misterio que se le abre al hombre por cuenta del conocimiento. Y para ese análisis el artista busca una forma de decir, de nombrar, de rehacer el mundo. Por eso a veces el arte se anticipa a la ciencia. Para Freud, por ejemplo, según declaró él mismo, sus grandes antecesores en los recodos del alma fueron Cervantes, Dostoievski y Thomas Mann. El oceanógrafo Jacques Cousteau se basó en el Nautilus de la novela de Julio Verne, Veinte mil leguas de viaje submarino, para poner en marcha su Calypso e inaugurar la exploración subacuática. Y Los primeros hombres en la luna, de H.G. Welles, contribuyó a infundir la conquista de nuestro satélite plateado.

En virtud de lo anterior, fácil es concluir que artistas y científicos procuran una expresión que dé cuenta de sus preocupaciones y resultados. Ciertamente, Zuleta (2003) amplía un poco más el panorama de la literatura para insistir en que la palabra del creador de mundos no solo existe para incomodar, criticar y emplazar al presente como al pasado, también es de su resorte proponer una nueva categoría que trascienda lo conocido:

la función de la literatura consiste más bien en crear un nuevo código por medio de las sugerencias y la evolución de la trama y los personajes, para crear de esta manera valores significativos nuevos sin apoyarse en los valores de un código ya existente. Si la literatura consiste solo en juzgar, desaparecería este carácter crítico porque éste se ejerce, precisamente, sobre ese código preexistente. Cualquier palabra que un novelista o poeta retome del lenguaje corriente está cargada de una significación moral y 
política; y lo que tiene que hacer el novelista es, precisamente, no recibirla regalada de la ideología en la cual ella existe sino crearle una significación nueva en su texto (p. 144).

De nuevo podemos constatar que la literatura se aproxima a la ciencia por cuanto ambas manifestaciones son creativas y exploratorias, una se centra en el alma, la otra en el mundo exterior, pero de igual forma procuran a su modo un nuevo conocimiento y someten al mundo, mediante sus respectivos instrumentos, a inéditas interpretaciones.

Y aun cuando al escritor de ficción se le escapasen los términos de expresión de esa epopeya científica para fijar el mundo y los acontecimientos contemporáneos, tiene a la mano, de todas maneras, la otra epopeya: la epopeya del lenguaje corriente, colectivo, de las masas; al autor le basta con entender lo que se contempla. Puede haber, y de hecho lo hay, un abismo casi insalvable entre el idioma de la ciencia y el de la literatura, sin embargo, ambos pretenden hacerse entender, y en esa necesidad encuentran una zona de mutuo auxilio y préstamo de instrumentales para la traducción de las nuevas realidades. Es, por consiguiente, destacable el notable esfuerzo de aggiornamento que se viene produciendo en la órbita de las letras, por ello cito in extenso a Alejo Carpentier (1990)

Escribir es un medio de acción. Pero acción que no es concebible sino en función de los seres a quienes concierne esta acción -los enciclopedistas franceses, Rousseau, Marx, Lenin, La historia me absolverá, hablándose de nosotros y de América latina. Pero si bien lo anteriormente citado -pienso más en El contrato social que en La nueva Eloísa- permanece ajeno al género novelístico, no debe olvidarse que, desde hace tiempo, la novela es considerada en función de utilidad, como materia excelente para estudiar las características de ciertas épocas y ciertas sociedades. (Proust cierra, en cuanto se refiere a indagación de una sociedad, un ciclo, revelador de los modos de vida, de los hábitos, de las ideas, de las aficiones, de una burguesía que entró en la novela francesa con el abate Prévost). Ahora bien: en el divorcio que se observa entre el epos técnico y el epos colectivo, el novelista, entendiendo su mundo, el epos que le es propio, que posee, que domina, puede todavía hacer escuchar su voz y hacer una labor útil.

La novela está muy lejos de estar muerta; independientemente del lenguaje técnico que acaso entienda mejor mañana, dispone todavía del lenguaje de cada día, lenguaje de los viejos narradores, que están aún lejos de haberse agotado en todos 
sus recursos. Se interesa en los hombres a los cuales el lenguaje técnico no dice todavía nada. Son numerosos estos hombres, muy numerosos. Tienen necesidad todavía del lenguaje claro de los viejos narradores, aunque ese lenguaje no cesa de evolucionar en función de un enriquecimiento traído por la necesidad de información política, los contactos con la historia presente, el auge de la etnología, la presencia de un cine, de un teatro, que ha poblado el universo de imágenes nuevas (pp. 265-266).

De tal suerte que ocuparse del mundo actual es, posiblemente, la función social del hacedor de realidades paralelas. O por lo menos una de esas funciones sociales. Es también de su competencia intentar comunicar su verdad mediante un lenguaje que recoja de modo comprensible y universal las preocupaciones del presente colectivo. Pero ¿cómo lleva a cabo el novelista la apropiación y transformación de los hechos de la realidad exterior? A través de la creación de unos actos que cobran sentido en el campo de la literatura y que se manifiestan por obra y gracia del lenguaje cotidiano, siempre sujeto a cambios permanentes.

También habría que anotar que la emancipación de la literatura de lenguajes técnicos, especializados y apartados de la comprensión general es en sí misma una postura rebelde digna de resaltar, pues su expresión no es de servidumbre, sino de, entre otras cosas, independencia y cuestionamiento.

Para continuar ejemplificando esa cercanía entre literatura y ciencia que vengo mencionando, cito una vez más a Zuleta (2003), pues sostiene que

Hay casos aislados en los cuales las contraposiciones entre ciencia y arte se disuelven y casos en que aparecen radicalmente separados y todo ello en el mismo sujeto. El primer caso lo analiza Freud en el discurso que hace cuando le otorgaron, en 1930, el premio Goethe de literatura, donde hace un alto elogio de Goethe. Muestra que su grandeza consiste en que logra mantener al mismo tiempo, en una época tan tardía como la suya, una actitud científica y una actitud artística, sin que en su vida el arte fuera una limitación para su actividad científica, ni su actividad científica se contrapusiera a la expansión de su personalidad artística, lo cual es una de las características más complejas y excelsas de la personalidad de Goethe (p. 165).

Hoy en día, a medida que los hombres de letras están mejor preparados para la transfiguración poética de materias científicas, 
los hombres de ciencia se permiten la licencia de aceptar a la poesía como parte de la explicación teórica de materias no exactamente literarias. Esa plasticidad que presenta la realidad (en sus pliegues íntimos y externos) es la que comunica los mundos de creadores y científicos en su empeño por establecer o descubrir universos organizados y henchidos de significado. Y aquí ya aparece la condición anfibológica del pensamiento complejo que me interesa resaltar al final de este trabajo.

\section{Intervención de los anfibios culturales}

Si la interdisciplinariedad es consustancial a la complejidad, con lo cual se favorece la integración de saberes, la construcción múltiple de la realidad y la implicación del sujeto en el objeto de su observación, es igualmente necesario que la interculturalidad intervenga en estas tareas por cuanto el contacto, los cruces y encuentros de distintas perspectivas culturales posibilitan la comunicación entre la órbita de las humanidades y la de las ciencias de la complejidad, con el objeto de otorgarle a estas una orientación, un sentido y una interpretación profunda.

No es que definitivamente las ciencias por sí mismas no puedan fijarse un derrotero y juzgar sus resultados ulteriores. Tampoco es que no puedan, en un momento dado, efectuar una reflexión sobre su ser y su hacer. Pero no es de resorte de las ciencias el convertir su práctica, su método, sus teorías, sus iniciativas y sus frutos en una meditación permanente y sistemática. Para ello han estado y están las humanidades y las artes. Ha sido la filosofía la que les ha otorgado a las ciencias un deber ser y ha ejercido una crítica sobre sus alcances y límites. Ha sido la ética la que ha discernido sobre la conducta humana. Los creadores y las artes, mediante alegorías y mundos paralelos, se han aproximado a la naturaleza, al hombre y a la cultura para organizarlos y modificarlos a su manera, así como el científico ha observado, experimentado, actuado y teorizado.

Para el caso que nos ocupa, sostengo que al menos dos de los autores examinados, Edgar Morin (2008), Boaventura de Sousa Santos (2009a), Rodríguez Zoya y Aguirre (2011), vendrían a cumplir la labor de pensadores de la ciencia, de estimuladores de una conciencia científica. A estos los enmarco dentro del dominio de anfibios culturales, según el término acuñado por Antanas Mockus (1994) en su texto Anfibios culturales, moral y productividad, por cuanto: 
Anfibio cultural es quien se desenvuelve solventemente en diversos contextos y al mismo tiempo posibilita una comunicación fértil entre ellos, es decir, transporta fragmentos de verdad (o de moralidad) de un contexto a otro.

Esa solvencia del anfibio cultural -capaz de obedecer a sistemas de reglas distintos en tiempos y en contextos diversos- hace que él deba ser un "camaleón". Por otro lado, el anfibio debe tener la capacidad de generar comunicación entre los diversos medios y tradiciones con los cuales entra en contacto. [...] Debe ser un intérprete (p. 127).

De este modo, creo que los anfibios culturales son decisivos por su capacidad de desenvolverse con naturalidad y eficiencia en diversos contextos culturales, al tiempo que facilitan la migración de conocimientos, modos e instrumentos de unas disciplinas a otras. Como su campo de acción son las ciencias sociales, las humanidades y aun las artes, la subjetividad es de crucial importancia, pues el diálogo no puede ser únicamente entre las ciencias, sino entre las ciencias, la naturaleza y el hombre. El hombre, entendido, por lo demás, como factor clave, jamás subalterno o disuelto en el marasmo de las conexiones, los elementos y las ecuaciones. Son ellos, los anfibios culturales, los que tal vez puedan acceder a lo sensible de la materia, y por lo cual puedan alcanzar un nivel muy cercano a lo que pretende en última instancia la complejidad: la contemplación del universo como una obra de arte, pero también como un signo por descifrar y un utensilio por humanizar en la medida que el hombre se humaniza por el uso del utensilio que en cierta forma es una obra de arte.

Son los anfibios culturales, a mi juicio, unos intérpretes de saberes, unos ensambladores de tradiciones, unos productores de metáforas y unos catalizadores cuya lealtad, si podemos Ilamarla así, está por encima de las deontologías, pues como lo menciona Mockus (1994) "El anfibio, en cuanto teje nexos y facilita procesos de reconocimiento de elementos de unidad humano en el mosaico mismo de la pluralidad de traiciones y proyectos, puede ser visto como una especie de integrador moral de la Humanidad" (p. 129). Esto, con el afán de evitar que las ciencias hegemónicas e históricas de Próspero apabullen las expresiones, intuiciones, formas y conocimientos del Calibán "salvaje", "a-histórico" y "antimetódico".

De modo que la carga moral de los anfibios culturales, para emplear el título de una célebre obra de Rudyard Kipling, 
La carga del hombre blanco -en la que Occidente tenía la obligación de conquistar a los pueblos bárbaros para civilizarlos-, debe consistir en rescatar del ostracismo la riqueza espiritual, cultural y los saberes tradicionales de los otros mundos, los mundos oscuros, híbridos, remotos, pero dinámicos, renovadores, informales, intuitivos, en donde la naturaleza humaniza al hombre.

Alrededor de esta labor ya hay toda una propuesta de recobro de nuestro pasado empírico y de nuestro hacer presente como de integración de conocimientos disímiles (taxativamente científicos o no) que cambiaría la dirección del saber que ha predominado en el mundo que es de las metrópolis del poder hacia las orillas, para ir de las orillas hacia esas metrópolis. La aproximación de mentalidades, experiencias, conocimientos, métodos y de pautas o reglas es la misión de esta categoría de exponentes interculturales.

Entonces, esta actividad anfibológica comporta diversos frentes: tender puentes teórico-prácticos, arrojar luces de carácter humanista y, sobre todo, pensar sobre el hacer, lo que pretendería, en resumidas cuentas, la hibridación de enfoques, sistemas y métodos para disponer de manera ponderada y creativa del conocimiento universal con el fin de adaptarlo a los ámbitos locales. La eticidad y la condición intercultural serían las fortalezas más destacadas de unos anfibios situados en medio de la diversidad, la fragmentación y los antagonismos.

La integridad moral y la formación intelectual de los anfibios culturales son factores que pueden brindar a la producción científica una reflexión filosófica, un sentido trascendente y una crítica acerca de sus finalidades. La fertilidad de la ciencia no solo está dada por la utilidad inmediata o mediata que pueda ofrecer. Ciertamente depende también del favor que le pueda prestar al género humano y de los deterioros que pueda evitar.

Esta ontología no seguiría los postulados "clásicos" europeos, más bien rescataría el concepto de comunidad, de compromisos horizontales, de respeto por los ancestros. Para la ciencia del Norte no hay tierra sagrada, para nuestras comunidades latinoamericanas la tierra sagrada no es un desperdicio, es un lugar en donde se toman decisiones y se reúnen los mayores a pensar en el bienestar general. Lo que alienta la ciencia clásica es el individualismo posesivo y el éxito de unos sobre el fracaso de muchos. 
Por lo anterior es que resulta imprescindible pensar acerca del papel de la ciencia y del científico en la sociedad, pues ni el científico es Moisés ni la ciencia, per se, es la panacea. Así como el conocimiento es generoso en la creación de aspectos benéficos para la humanidad, igualmente es fecundo en distribuir aspectos abiertamente perjudiciales.

En efecto, la consciencia no debe estar divorciada de la producción científica, porque un conocimiento irresponsable acarrea consecuencias devastadoras. En atención a este punto neurálgico cito ampliamente

La responsabilidad es una noción humanista ética que sólo tiene sentido para un sujeto consciente. Ahora bien, la ciencia, en la concepción "clásica" que rige todavía en nuestros días, pone en disyunción por principio hecho y valor, es decir, elimina de su seno toda competencia ética, funda su postulado de objetividad en la eliminación del sujeto del conocimiento científico. No proporciona ningún medio de conocimiento para saber qué es un "sujeto". La responsabilidad es, pues, no-sentido y no-ciencia. El investigador es irresponsable por principio y tarea. Al mismo tiempo, el problema de la responsabilidad escapa a los criterios científicos mínimos de control que tienden a guiar la distinción de lo verdadero y de lo falso. Está entregada a las opiniones, convicciones, y si cada uno pretende y cree tener una conducta "responsable", no existe ni fuera de la ciencia ni en la ciencia un auténtico criterio de la "verdadera" responsabilidad. Así, Einstein se creyó profundamente responsable ante la humanidad cuando, en los primeros momentos, luchó contra todos los preparativos militares. Todavía se sintió responsable ante la humanidad cuando intervino encarecidamente en la fabricación de la bomba atómica. El ejemplo de Einstein es esclarecedor. El espíritu más genial no dispone de las condiciones que le permiten pensar la ciencia en la sociedad, es decir, conocer el lugar y el papel de la ciencia en la sociedad (Morin, 1984, pp. 87-88).

Si esto es así, mal haría el científico en darse el lujo de ser un competentísimo físico, químico o genetista y ser, al mismo tiempo, un autista ético. Hay que convenir en que semejante contradicción es una tragedia para el conocimiento y para el hombre. Y es, precisamente, esa toma de consciencia crítica, uno de los factores decisivos que definen a los anfibios culturales, quienes ponen en el centro de la discusión sobre el sentido de la ciencia la necesidad de superar el aislamiento y la obligación de adoptar una conducta responsable. De lo que se trata aquí es de impedir la deshumanización de la razón. 
Por ello afirmo que Boaventura de Sousa Santos (2009b) es un miembro de esta comunidad humanística, porque a partir de su epistemología del Sur defiende una reinvención del conocimiento que, basada en el sentido común, el saber local y la inteligencia comunitaria, "privilegian la acción que no produzca rupturas significativas en lo real" (p. 55). Más aún para él, conocimiento y tecnología deben traducirse en sabiduría para la vida, porque esta señala los marcos de prudencia a nuestra aventura científica.

En este punto recupero la reflexión que hace de Sousa Santos (2009b) en Una epistemología del Sur: la reinvención del conocimiento y la emancipación social sobre el valor crucial de las humanidades para volver a pensar la realidad

La superación de la dicotomía ciencias naturales/ciencias sociales tiende así a revalorizar los estudios humanísticos. Pero esta revalorización no ocurrirá sin que las humanidades sean ellas también profundamente transformadas. Lo que habrá en ellas de futuro será lo que haya resistido a la separación sujeto/ objeto y lo que haya preferido la comprensión del mundo a la manipulación del mundo. Este núcleo genuino fue, no obstante, atrapado en un cerco de preocupaciones mistificadoras (el esoterismo excéntrico y la erudición vacía). [...] Habrá que recuperar ese núcleo genuino y ponerlo al servicio de una reflexión global sobre el mundo (p. 46).

Si entiendo bien, de Sousa Santos se muestra partidario colocar al hombre en todo el centro del conocimiento para que el aparato tecnocientífico no se desborde y "enloquezca". Esta es, a mi juicio, una posición moral, cultural y, desde luego, política. Posición propia de lo que defiendo aquí como labor de los anfibios culturales. Siendo esto así, creo que el gran aporte al pensamiento científico de Sousa Santos, y de quienes comparten su postura, es la responsabilidad social del conocimiento. Frente a un proyecto de mundo de las grandes universidades internacionales, de los conglomerados farmacéuticos y de las grandilocuentes predicciones económicas, de Sousa responde con una epistemología que le reconoce legitimidad a los saberes locales, que da crédito al empirismo popular, que da voz a aquellos que resisten los embates de la naturaleza como la acción hostil de los poderosos. La ciencia para él necesaria es la que pueda dialogar con los saberes campesinos, afros, indígenas y desembocar, según de Sousa Santos (2009) en "la filosofía de la práctica" (p.21). 
Entonces, al concepto de anfibios culturales se suman de Sousa Santos y Morin, por cuanto se han dado a la tarea de establecer vasos comunicantes entre las ciencias y la sociedad. De manera tal que han intentado traducir las nociones más abstractas de las ciencias a un lenguaje potable que resulte comprensible para una buena porción del público lego, aunque interesado por el mundo del conocimiento.

Enclaustrarse la ciencia en la torre de marfil y no compartir con la sociedad los debates y resultados del saber es arriesgarse a caer en el absolutismo es darle la espalda al conglomerado que inevitablemente recibirá los efectos de sus investigaciones y descubrimientos, sería la negación del gesto cultural por excelencia: la transmisión de la inteligencia.

Por eso se requiere que las ciencias se integren al mundo, porque el mundo (del arte, de las humanidades, de los pueblos periféricos) también tiene algo que decir al respecto. Especialmente el tercer mundo. Y aquí me tomo la libertad de traer a cuento la sociología sentipensante latinoamericana o sociología de la liberación, noción desarrollada por Orlando Fals Borda a finales de los años 60, para denotar a aquellas personas que combinan razón y pasión, cuerpo y corazón en todo lo que realizan.

Al ampliar su idea sobre la descolonización intelectual que se está efectuando en América Latina, dice Fals Borda, según lo retoma Moncayo (2009) en su obra Una sociología sentipensante para América Latina. Orlando Fals Borda. Antología

Los euroamericanos, evidentemente, progresaron y se enriquecieron con el desarrollo científico-técnico, mucho a expensas de nosotros los del Tercer Mundo. Pero ello fue también expensas de su alma y de los valores sociales, como en el contrato mefistofélico. Ahora, después de haber botado la Ilave del arca del conocimiento prístino de donde partió el progreso, hastiados de éste por la forma desequilibrada que tomó, y avergonzados de la deshumanización resultante, los nuevos Faustos pretenden reencontrar la llave del enigma en las vivencias que todavía palpitan en las sociedades Ilamadas atrasadas, rurales y primitivas, donde existe aún la praxis original no destruida por el capitalismo industrial: aquí en América Latina, en África, en Oceanía (p. 368).

Lo anterior demostraría que el curso de la influencia cultural, académica y de las ciencias sociales estaría cambiando para 
dejar de ser de Norte a Sur, como ha venido ocurriendo tradicionalmente, y tomar el sentido contrario de Sur a Norte. En cuyo caso, anota Fals Borda en la obra de Moncayo (2009)

Lo que estaríamos observando sería realmente el comienzo de una hermandad universal comprometida políticamente contra sistemas dominantes, una hermandad conformada por colegas intensamente preocupados por la situación social, política, económica y cultural de todos los que heredamos este mundo injusto, deforme y violento, allá como acá, y que queremos cambiarlo de manera radical (p.372).

Esos "colegas intensamente preocupados", que menciona Fals Borda, según consta en la obra de Moncayo (2009), no son otros, a mi juicio, que los anfibios culturales que propongo para que procuren no solo tender puentes entre las ciencias de la complejidad y el pensamiento complejo a la luz de una ética y una orientación trascendente, humanista y aun humanitaria, en el sentido del rescate, preservación y dignificación del conocimiento popular, afro, indígena y campesino del tercer mundo, sino también para lograr que científicos e intelectuales del Norte y del Sur converjan, como dice Fals Borda en el texto de Moncayo (2009)

Creadoramente con novelistas y poetas para abrir surcos nuevos de comprensión del cosmos y retar versiones facilistas y parciales del conocimiento que provienen de la rutina académica o universitaria. Los Macondos junto con los bosques brujos yanquis, las selvas de los Mundurucú y los ríos-anaconda de los tupis son símbolo de la problemática tercermundista y de la esperanza euroamericana: reúnen lo que queremos preservar y lo que ansiamos renovar (p. 373).

Como se ve, la tesis de Fals Borda, citada por Moncayo (2009), se endereza por el mismo camino de la "insurrección de conocimientos subyugados" de Foucault, en la que se explica la reacción a la tendencia erudita de producir un solo cuerpo unitario de teoría como si fuera la ciencia, olvidando otras dimensiones de la realidad como las luchas populares no registrada oficial ni formalmente.

Lo que también se busca con la intervención de los anfibios culturales tiene que ver con la superación de ciertos escollos y atavismos que formula Fals Borda en la antología realizada por Moncayo (2009) 
Dejar atrás a dos tétricos hermanos, el positivismo y el capitalismo deformantes, para avanzar en la búsqueda de formas satisfactorias de sabiduría, razón y poder, incluyendo las expresiones científicas que las universidades, las academias y los gobiernos han despreciado, reprimido o relegado a segundo plano (p. 377).

De manera que los anfibios culturales, considero, pueden contribuir a fomentar posiciones altruistas, éticas, ecuménicas, creativas y humanistas que se compadezcan con el bienestar humano, pues no podemos desconocer que en Occidente ha existido una tradición de filósofos y científicos que han pretendido escapar de la visión hobbesiana de la sociedad según la cual "el hombre es un lobo para el hombre". Si algo intentó Francis Bacon fue crear una tecnología humanista. Seguramente Descartes no imaginó los desastres ecológicos que se desprenderían de sus reglas de análisis positivo. Imposible que Galileo se hubiera imaginado que la matematización de la naturaleza inaugurada por él condujera a la bomba atómica.

\section{Ética, compromiso y duda permanente}

Si estamos de acuerdo sobre esto, los anfibios culturales pueden ser los más indicados para que le impriman un sentido a las tecnociencias, pues, como sabemos, no tienen vida propia y adoptan los significados que les atribuyamos. Desde luego, estos asuntos teórico-prácticos son de suma importancia y gravedad, y por su calado y dimensión deben y tienen que ser abordados por pensadores y creadores, aquellos que desde siempre han tratado de conciliar conocimiento y acción, a partir de una responsabilidad intelectual, social y ética.

Al respecto, Morin (2008) dice en su texto Complejidad restringida y Complejidad generalizada o las complejidades de la Complejidad

Cuando nosotros introducimos la ciencia en las tecnologías, nosotros podemos saber la fuerza formidable de la tecnociencia, una fuerza que es incontrolable. Entonces, la conclusión es, pienso, que de estas revoluciones debe salir una Ciencia Nueva. Estas palabras son de Jean Bautista Vico, filósofo italiano del siglo XVIII. Para él, la Ciencia Nueva era una ciencia meta-cartesiana, que introduce también el porvenir, la historia de la ciencia. La Nueva Ciencia (...) es una posibilidad 
de religar y de fecundación, porque una disciplina fuera de su medio no puede ser útil a nadie, ni a los ciudadanos, ni a los humanos. Por esta razón el conocimiento complejo necesita una transdisciplinariedad, y que la transdisciplinariedad necesita un pensamiento complejo. Todo esto presupone que se debe hacer una reforma del conocimiento, una reforma del pensamiento (p. 39).

De esta forma, Morin (2008) comparte las preocupaciones y los intereses de los anfibios culturales con relación a las ciencias y al cometido del pensamiento complejo. De una parte, que estas, divorciadas unas de otras, difícilmente podrán prestar un servicio a la humanidad, pues cada una por su lado defenderá su propio patio sin pensar en el bien mayor que podría prestar al coaligarse con las demás. De otra parte, que, al amparo del pensamiento complejo, la transdisciplinariedad podrá contribuir a la reforma del pensamiento de, según sostiene Morin (2008) en su texto Complejidad restringida y Complejidad generalizada o las complejidades de la Complejidad

Tener una visión más controlada de las posibilidades de la acción, y de utilizar una estrategia más que un programa, un programa no se cambia, la estrategia puede cambiar, y saber, porque hoy día se sabe mucho, utilizar un principio, el principio de la precaución. [...] El porvenir tiene una etapa especial que tiene los cuatro motores incontrolables: ciencia, tecnología, economía y política (p. 40).

Es decir, que bien mirado el planteamiento de Morin, la ética, la cultura y la conciencia de la catástrofe son fundamentales para llevar a cabo una planetarización en sentido contrario a la que avanza como una aplanadora por el mundo entero: me refiero a la globalización neoliberal. Esa otra planetarización o globalización a la que alude Morin (2008) en su obra anteriormente citada es

Una ética de la comprensión, la comprensión de los otros, de no reducir, de tender a eliminar el maniqueísmo que ve a los otros como todos buenos y los otros todos feos. Es una comprensión que tiene consecuencias éticas inconmensurables, consecuencias políticas, otro modo de combinar la organización social (p.40).

Lo anterior remite, hasta cierto punto, a la idea sartreana de compromiso (engagement), es decir, aquella acción del 
intelectual que toma conciencia de la sociedad y del mundo en que le tocó vivir y, además, pone su pensamiento al servicio de una causa determinada. Es el compromiso que interviene de manera activa, incluso de modo radical en la sociedad para transformarla, liberarla de su antiguo ropaje.

Esta misma línea de trabajo de emancipación científica se observa con ímpetu en América Latina. Con razón Moncayo (2009) acoge a Fals Borda

El compromiso-acción es ideológico e implica una visión dentro de la ciencia. Esta visión está condicionada por pautas sociales y por trascendentales cambios políticos que llevan a los científicos a una evaluación de su disciplina y a una reorientación de la misma. De este proceso van resultando no sólo la acumulación del conocimiento sino también su enriquecimiento, su renovación, su revitalización.

Éstas son las coyunturas que se presentan hoy a los científicos sociales ante la crisis de América Latina, para justificar su tarea y la existencia misma de la ciencia. Son una prueba de decisión, de laboriosidad y de creatividad en la presente etapa histórica. Son una prueba que lleva a combinar el rigor científico con la participación en el proceso histórico, para lograr una postura intelectual autónoma, aunque ella pueda acarrear persecuciones e incomprensiones momentáneas. Quizá de estos empeños resulte no sólo una ciencia social más respetable, firme y propia nuestra, son una más clara definición de la crisis latinoamericana, sino también una política eficaz de cambio que lleve a una sociedad superior a la existente. Tal es la responsabilidad de los hombres de ciencia, y tal el engagement que adquirimos ante el mundo y ante la historia (p. 252).

Son por eso los pensadores y los creadores, es decir, los anfibios culturales, a quienes les compete, si adoptamos las palabras de Heidegger (1966) sobre el papel de la filosofía, "pensar y cuidar de que el hombre sea humano y no in-humano, esto es, fuera de su esencia. [...] Si se entiende generalmente bajo 'Humanismo' el esfuerzo porque el hombre sea libre para su humanidad y encuentre en ello su dignidad" (p.14).

Pues ni la libertad ni la dignidad del hombre se hallan en el biologismo como tampoco se puede alegar que la esencia del hombre descanse en ese "organismo" que la física, la química o la cibernética intentan explicar. Con razón Morin (2008) refiere que 
Nosotros tampoco podemos aislar la ciencia de su contexto social. No únicamente porque hoy día el desarrollo de la tecnociencia tiene una intervención mayor en el provenir de la humanidad, se transforma el poderío con las posibilidades maravillosas de la ciencia, pero también con la posibilidad de destrucción que tienen las armas nucleares. No podemos entender la historia de la ciencia de un modo aislado, también la ciencia requiere de procesos sociales. Pienso que el pensamiento, el pensamiento complejo, muestra que las cosas separadas, se quedan separadas, pero al mismo tiempo son inseparables. Nosotros, los seres humanos, si pensamos que tenemos en nosotros partículas de los primeros momentos del Universo, y que nuestro cuerpo tiene átomos de carbono que se hicieron de la unión de tres núcleos de helio en una estrella anterior al sol, [...] si pensamos que toda la historia de ña evolución de la vida está en nosotros; entonces, nosotros expresamos el principio hologramático, la totalidad del Universo se encuentra en un todo singular, nuestras personas singulares (p. 38).

Esta síntesis del hombre con el universo constituye la mayor expresión de integración entre las ciencias y el pensamiento, y supone también el hecho de que, sin el rasgo fundamental de la subjetividad y la interpretación, el mundo y el hombre pierden sentido, porque el designio del conocimiento es el de construir camino a medida que se camina, como también hacerse a un lado del camino para representarlo y pensar acerca de él. Son estas, igualmente, las dos dimensiones de los anfibios culturales: por un lado, la de reunir durante el camino, y, por el otro, la de contemplar el trayecto a la vera del camino para pensar sobre el carácter, las condiciones, las posibilidades y los límites del camino. Es el hombre el eterno peregrino del ser y del universo. Siempre en movimiento, como el pensamiento, como el mundo; pero con puentes, para no perder el camino, para vivir intercomunicado, para seguir siendo mientras se camina, traspasando fronteras no solo científicas, también geográficas, pues como dice Heidegger (1966) en Carta sobre el humanismo "La apatridad se convierte en destino del mundo" (p. 38), es decir, que el hombre, en su búsqueda de conocimiento y de sí mismo no reconoce cortapisas, porque su fin es la totalidad. El partido del hombre es el hombre mismo. El homo humanus, más allá del homo economicus, del homo cientificus, del homo politicus. Claro que con una preferencia especial por el hombre de los extrarradios. 
Y para no desperdiciar esta alusión a Heiddeger, creo oportuno señalar que mi invocación recurrente a la ética va en el mismo sentido del filósofo alemán, sobre todo cuando sostiene que

El deseo de una Ética asedia tanto más fervorosamente cuanto que la notoria desorientación del mundo, no menos que la negada, crece hasta lo inconmensurable. Todo cuidado debe ser dedicado a la unión por la Ética, pues el hombre de la técnica, librado a la masa, solo puede aún ser traído a una segura constancia de su planear y obrar en total, mediante un recogimiento y ordenación correspondiente a la técnica. ¿Quién puede pasar por alto esta penosa situación? ¿No debemos nosotros tratar con cuidado y asegurar los compromisos existentes, también aunque ellos mantengan al hombre tan en penuria y en el simple hoy? Ciertamente. ¿Pero exime esta penuria de pensar aquello que sigue siendo además lo por-pensar y en cuanto el ser sigue siendo antes que todo garantía y la verdad para el ente? ¿Puede además el pensar rehuir el pensar del ser, después de que éste ha estado oculto en largo olvido y que a la vez, en el actual momento del mundo, se anuncia por el estremecimiento de todo ente? (pp. 54-55).

Es decir, no podemos entregar el destino del hombre a las fuerzas indiferentes e incluso nihilistas de la tecnociencia: fuerzas que, al obrar como si el mundo estuviera en una órbita extraña al ser humano, no buscan más justificación que el rendimiento y el éxito en el sentido más prosaico y miserable de estos términos. Es por esto que la ética es parte sustantiva del quehacer, incluso anterior a este, pues sin su iluminadora participación el hombre está echado a perder. Al pensar sobre la ética de las ciencias, el hombre custodia su propia humanidad, que para ser conservada en su integridad se proyecta más allá de toda praxis. De manera que el logos no puede ser otra cosa que la afirmación del ethos, del comportamiento consecuente del hombre.

Por otra parte, el ethos le impone al hombre el deber de velar por la salud del mundo, pues no vive fuera de él, sino que se encuentra indefectiblemente vinculado a la totalidad de la vida y del entorno. La ética, por lo menos la heideggeriana, no ve como opuestos conocimiento y Naturaleza, sino, más bien, una relación de mutua influencia. Es la de Heidegger la ética de la convivencia y del respeto, no es ni por asomo la continuación de la ética metafísica, aquella en la cual predominaba la visión antropocéntrica. 
Así, podemos considerar que la ética heideggeriana es la más adecuada a las necesidades de la complejidad, porque en vez de promover dicotomías, reclama, a partir de la vivencia misma, de la actitud sólita, la reinvención de las relaciones entre el hombre y el cosmos. Tolerancia, cuidado y comprensión, podrían ser las solicitudes condignas a esta ética para nuestros actuales tiempos de penuria. Dicho de otra manera, el hombre ya no es el lugar de la verdad, lo es todo, con el hombre como parte del todo.

En últimas, esta ética es la mayor manifestación de la precariedad del hombre, de su tremenda vulnerabilidad. Por consiguiente, no está mal desconfiar de la razón, de la razón científica, de la razón derivada del conocimiento, de la razón contemporánea, para someterla de cuando en cuando a un severo examen de carácter ético, porque como declaraba Goya: la razón produce monstruos. En ese sentido, retomo las palabras de Estanislao Zuleta (1991) acerca de los peligros de una inteligencia sin contrapesos

Ya en 1916 Thomas Mann había vislumbrado una cosa muy interesante y era la acusación a la razón como causa de la peor opresión. La razón que quiere organizar a la sociedad, que toma a la sociedad como un objeto de sus manipulaciones organizadoras, que no quiere que nada se escape, termina siendo el totalitarismo. La sociedad es un objeto que hay que organizar racionalmente, y todo lo que se escape del propósito, se declara irracional (pp. 90-91).

En consecuencia, la ética heideggeriana es escéptica por principio, pues conmina al hombre a dudar de sí mismo, a desmarcarse del rebaño, a dejar de ver el mundo como a su peor adversario. En cualquier caso, Heidegger invita a que cada quien piense por sí mismo y no dependa de la tutela de nada ni de nadie. Quiere que antes bien sospechemos.

No quiero cerrar mi discurso sin alegar que sin lugar a dudas existen no pocos hechos, fenómenos y organizaciones que no pueden explicarse en los laboratorios y que parecen estar más allá de las ecuaciones, las fórmulas y las combinaciones aleatorias o forzadas. Son hechos, fenómenos y organizaciones que por ahora no se pueden demostrar, como durante mucho tiempo no se podía probar que las chispas que despedían en las noches las ropas de lana eran provocadas por la electricidad. Sin embargo, la electricidad estaba en el cuerpo del hombre, en el ambiente, en las cosas. Y más tarde fue el motor de la 
industrialización. Así ocurre hoy con otra clase de "espectros" o "alucinaciones" que rodean al hombre y al mundo y con los cuales no se puede experimentar del modo como nos ha enseñado la ciencia. Ello no significa que tales "espectros" y "alucinaciones" no sean reales, aunque no encuentren sitio en nuestros mapas del conocimiento, pues de esos "chispazos" da cuenta la literatura, al igual que el resto de las artes. Permanentemente las letras están despejando las opacidades del hombre y su ámbito. Tal como lo hace la ciencia. Lo que varía es la idea de realidad que tiene cada una de estas formas de aproximación a lo que por demasiado tiempo llamamos "verdad" y que no es más que el entramado de la realidad, que en ocasiones se nos presenta como pavesas de lo "sobrenatural".

Por lo hasta aquí expuesto, considero que los anfibios culturales pueden ejercer una suerte de magisterio social con el fin de mantener viva una vieja e intermitente alianza entre la órbita del sacerdocio científico y la asamblea ciudadana. El suyo es el trabajo de Sísifo, la cuesta que el hombre remonta desde que el mundo es mundo para volver a empezar una y otra vez. Es el de los anfibios culturales (pensadores y creadores), un esfuerzo permanente e incompleto, pero imprescindible.

\section{Conclusiones}

Si la literatura no es un lujo ni un adorno, sino más bien una forma de apreciar e iluminar la vida, de acercar las mentes y los corazones de los hombres al misterio, entonces es plausible pensar que el arte de las letras tiene la capacidad de articular lo que en la vida aparece como inconexo, arbitrario, azaroso y sin sentido. Esa libertad, que también comparte con la ciencia, de ordenar, intercomunicar, sistematizar e interpretar la realidad, obra como una especie de catalizador, pues en últimas lo que procura la literatura es otorgar un sentido al quehacer del hombre. Y dentro de ese quehacer se encuentra, naturalmente, la producción científica, producción que no se detiene para pensar sobre sí misma y sus diversas consecuencias. No es de resorte de la ciencia adelantar una ontología acerca de su actividad, en cambio, sí es parte de la esencia de las letras reflexionar sobre todo aquello que le concierne al hombre. En contrapartida, lo que le concierne a la ciencia es la órbita de la materia, en la que el hombre, esencialmente, es una máquina biológica más en el concierto de las cosas. 
Por otro lado, si alguna función le cabe a la literatura, esa es la de darle la palabra al mundo, mediar entre los hombres y vincular a estos con su ámbito. De modo pues que, al igual que la ciencia, analiza, describe, abstrae, particulariza y universaliza. Pero a partir de una diferencia acerca de la cual cayó en cuenta Kafka: la literatura rompe el mar helado dentro de nosotros. Esto es, que el arte trabaja con base en las emociones, las interioridades, las intuiciones y percepciones del ser humano para recrear las experiencias privadas de cada uno de nosotros. Mientras que la materia prima de las ciencias no es otra que las experiencias públicas, todo aquello que ocurre fuera de nosotros, de nuestras ideas y sentimientos.

Después de todo, bien se podría preguntar ¿qué beneficios ha recibido la humanidad de la literatura para mejorar su tránsito en la tierra? Una respuesta podría consistir, por ejemplo, en que la novela Frankestein de Mary Shelley advirtió de las pesadillas monstruosas que puede crear la razón. Otra respuesta apuntaría a la sátira de sucesos ridículos que es Bouvard et Pécuchet de Flaubert, en la que se advierte cómo avanza la ciencia sin que se comprendan los resultados de su praxis y sin que la ciencia se percate del curso del mundo.

En virtud de todo lo anterior, se puede sostener que la literatura es en sí misma pensamiento complejo, pues no solo es una representación de la realidad y una proyección de la abstracción del escritor, es todo un sistema de relaciones que incluye al observador en lo observado, es un sistema (estético y autónomo) integrado a otros como son la cultura, la sociedad, la política, etc. Es, por consiguiente, un medio de conocimiento del mundo para repensar lo conocido; conoce para innovar, para crear, para anticipar.

Cabe afirmar, igualmente, que en la escritura narrativa, tal como sucede en el método propuesto por Edgar Morin, es posible reconocer la presencia del sujeto que busca, conoce y piensa. La literatura, como propone la complejidad, no simplifica, no es inmóvil, no excluye; antes bien profundiza, amplifica e integra a los contrarios. Es la literatura un frente más del pensamiento complejo por cuanto construye una imagen del hombre y del mundo a partir de fuentes, elementos, influencias, intuiciones e imaginación, para crear un mundo no solo paralelo sino complementario y preñado de significado. Al fin y al cabo, diferencias al margen, ciencia y literatura desean desvelar lo oculto, de la materia, la primera, y del espíritu, la otra. 


\section{Referencias}

Cuadra, P. (s.f.). Pablo Antonio Cuadra - Poéticas. Recuperado de https://www.google.com/search?rlz=1C1CHBD_esCO7 89CO789\&ei=R0QiXorNOIXX5gKtIZDADA\&q=encontrar+ la+poes $\%$ C $3 \%$ ADa+de+las+cosas+corrientes $\% 2 \mathrm{C}+$ pablo+ antonio+cuadra\&oq=encontrar+la+poes $\%$ C3\%ADa+de+la s+cosas+corrientes $\% 2 \mathrm{C}+$ pablo+antonio+cuadra\&gs_l=psyab.3...2030.26

De Sousa Santos, B. (2009b). Hacia una epistemología más allá de lo posmoderno. En B. de Sousa Santos. Una epistemología del Sur: la reinvención del conocimiento y la emancipación social (pp. 16-59). México: Siglo XXI.

Heidegger, M. (1966). Carta sobre el humanismo. Madrid:Taurus ediciones.

Huxley, A. (1966). Literatura y ciencia. Barcelona: E.D.H.A.S.A.

Kundera, M. (1994). El arte de la novela. Barcelona: Tusquets Editores.

Mockus, A. (1994). Anfibios culturales, moral y productividad. Revista colombiana de psicología, 3(3), 125-135.

Moncayo, V. (2009). Una sociología sentipensante para América Latina. Orlando Fals Borda. Antología. Bogotá: Siglo del Hombre Editores y CLACSO.

Morin, E. (1984). Ciencia con consciencia. Barcelona: Anthropos, Editorial del Hombre.

Morin, E. (2008). Complejidad restringida y Complejidad generalizada o las complejidades de la Complejidad. Pensando la complejidad, 5, pp. 27-41.

Morin, E. (1999). El paradigma de la complejidad. En E. Morin. Introducción al pensamiento complejo (pp. 87-131). Buenos Aires: Gedisa.

Nietzsche, F. W. (2011). El origen de la tragedia. México, D. F.: Editorial Porrúa. 
Rodríguez, L., y Aguirre, J. (2011). Teorías de la complejidad y ciencias sociales. Nómadas. Revista Crítica de Ciencias Sociales y Jurídicas, 30(2).

Zuleta, E. (1991). Colombia: Violencia, democracia y derechos humanos. Bogotá: Altamir Ediciones.

Zuleta, E. (2003). Thomas Mann, la montaña mágica y la llanura prosaica. Medellín: Hombre Nuevo. 